E ISSN: 2622-223X

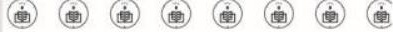

P ISSN: 2598-7607

Vol. II No. 01 (Maret - September) 2017

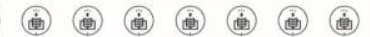

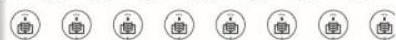

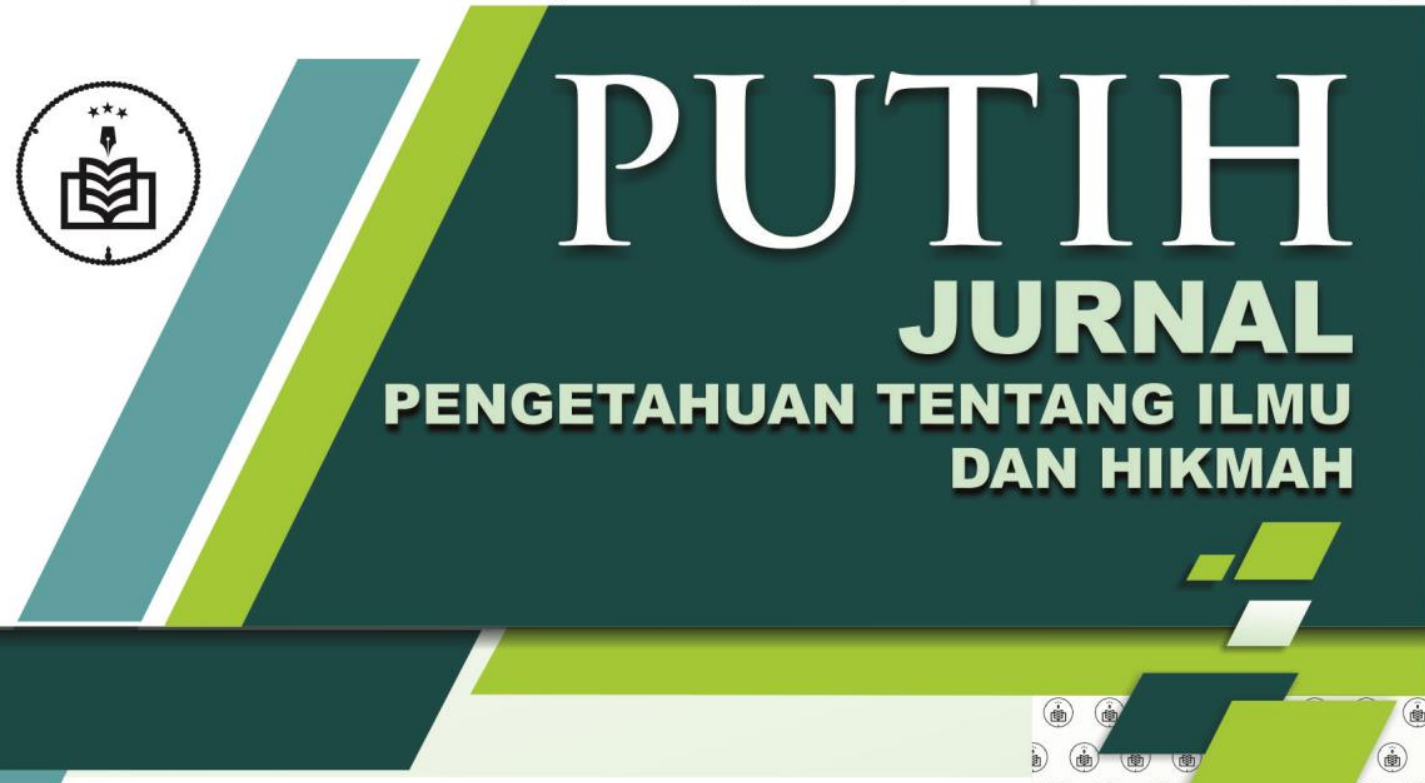

\section{HAKIKAT DOA}

Muhammad Husein Basofi 1-22

- MANAQIB SYEIKH ABDUL QADIR SEBAGAI MEDIA SULUK Durrotun Hasanah 23-42

- RELASI ANTARA AKAL DENGAN HATI PERSPEKTIF KH. ACHMAD ASRORI AL-ISHAQY Irwanto 43-64

- RELEVANSI AJARAN BUDHA DAN TASAWUF Mohammad Arista 65-100

- TERAPI SPIRITUAL MELALUI TAZKIYAH AL-QALB PERSPEKTIF ULAMA SHUFIYYAH

Anas Fajriansyah 101-122 (19i) (1) (19)

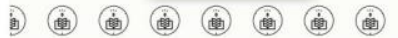

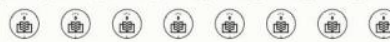

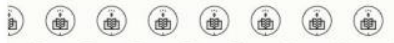

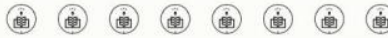

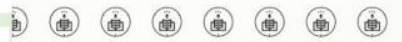

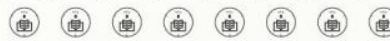

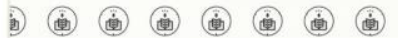

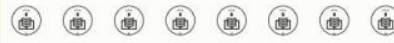
ib) (iii) (iii) (ii) (ii) (iii) (iii) (iit)

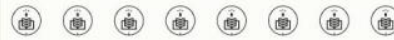

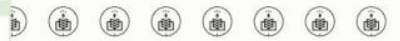

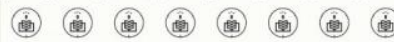

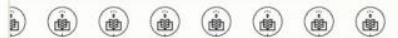

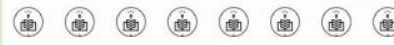

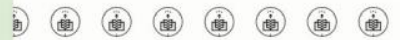

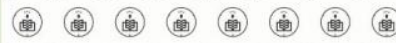

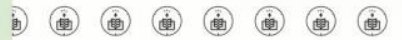

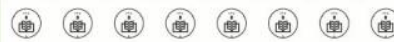
diterbitkan :

MA'HAD ALY

PONDOK PESANTREN ASSALAFI AL FITHRAH Surabaya 2017

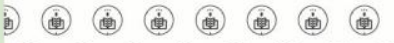

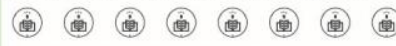
ib) (ii) (ii) (ii) (ii) (ii) (ii) (iii)

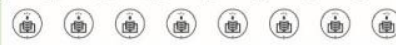
ib) (ii) (iii) (ii) (ii) (ii) (ii) (ii)

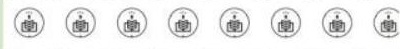

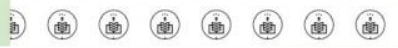




\section{REDAKTUR PUTIH \\ JURNAL PENGETAHUAN TENTANG ILMU DAN HIKMAH}

Ijin terbit

SK. Mudir Ma'had Aly No. 18/MAy-PAF/II/2017/SK

PENGARAH

Muhammad Musyafa'

Abdur Rosyid

Ahmad Syathori

Fathur Rozi

PIMPINAN REDAKSI

Fathul Haris

DEWAN EDITOR

Achmad Imam Bashori

ANGGOTA

Mustaqim

Samsul Arifin

Abdul Hadi

Alamat Penyunting dan Surat Menyurat :

Jl. Kedinding Lor 99 Surabaya

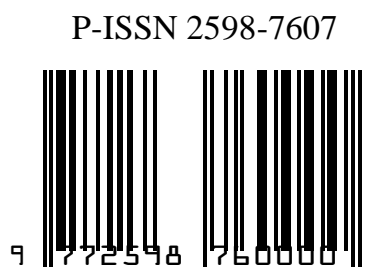

E-ISSN: 2622-223X

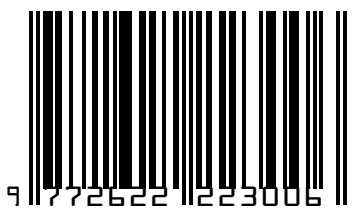

diterbitkan

MA'HAD ALY

PONDOK PESANTREN ASSALAFI AL FITHRAH

Surabaya 


\section{DAFTAR ISI}

DAFTAR ISI

— PEDOMAN TRANSLITERASI

ם HAKIKAT DOA

Muhammad Husein Basofi 1-22

— MANAQIB SYEIKH ABDUL QADIR SEBAGAI MEDIA SULUK

Durrotun Hasanah 23-42

RELASI ANTARA AKAL DENGAN HATI PERSPEKTIF KH. ACHMAD ASRORI AL-ISHAQY

Irwanto 43-64

- RELEVANSI AJARAN BUDHA DAN TASAWUF Mohammad Arista 65-100

TERAPI SPIRITUAL MELALUI TAZKIYAH AL-QALB PERSPEKTIF ULAMA SHUFIYYAH

Anas Fajriansyah 101-122 


\section{PEDOMAN TRANSLITERASI}

Berikut ini adalah skema transliterasi Arab-Indonesia yang ditetapkan dalam penulisan jurnal ini:

\begin{tabular}{|c|c|c|c|c|}
\hline $\mathrm{NO}$ & ARAB & INDONESIA & ARAB & INDONESIA \\
\hline 1 & 1 & 6 & b & t\} \\
\hline 2 & ب & B & ظ & $\mathrm{Z}\{$ \\
\hline 3 & ت & $\mathrm{T}$ & $\varepsilon$ & 6 \\
\hline 4 & ث & $\mathrm{Th}$ & $\dot{\varepsilon}$ & gh \\
\hline 5 & ج & $\mathrm{J}$ & ف & $\mathrm{F}$ \\
\hline 6 & $\tau$ & $\mathrm{h}\{$ & ق & Q \\
\hline 7 & $\dot{\tau}$ & $\mathrm{Kh}$ & 5) & $\mathrm{K}$ \\
\hline 8 & د & D & J & $\mathrm{L}$ \\
\hline 9 & j & $\mathrm{Dh}$ & r & $\mathrm{M}$ \\
\hline 10 & $\jmath$ & $\mathrm{R}$ & ن & $\mathrm{N}$ \\
\hline 11 & j & $\mathrm{Z}$ & 9 & W \\
\hline 12 & س - ل س & $S$ & a & $\mathrm{H}$ \\
\hline 13 & ش & $\mathrm{Sh}$ & $s$ & , \\
\hline 14 & ص & $s\{$ & ي & $\mathrm{y}$ \\
\hline 15 & ض & $d\{$ & & \\
\hline
\end{tabular}

Untuk menunjukkan bunyi hidup panjang (madd) dengan cara menuliskan coretan horizontal di atas huruf a, i>dan $u>($ ) $116)$. 


\title{
TERAPI SPIRITUAL MELALUI TAZKIYAH AL-QALB \\ PERSPEKTIF ULAMA SHUFIYYAH
}

\author{
Moch. Anas Fajriansyah ${ }^{158}$ \\ Email: fajrian.elnawi@gmail.com
}

\begin{abstract}
ABSTRAK
Tasawuf adalah cara untuk membersihkan hati dariapa yang telah menggangu, memadamkan sifat-sifat kelemahan sebagai manusia biasa, menjauhi segala sesuatu yang berkaitan dengan hawa nafsu dan mendekatkan kepada sifat-sifat suci kerohanian. ${ }^{159}$ Al-Tazkiyah bermaksud pembersihan atau penyuburan, dalam konteks ahli tasawuf Tazkiyah merujuk kepada bersih daripada segala sifat keji dalam diri atau hati yang memerlukan usaha gigih dan bersungguh-sungguh bagi sesorang menyingkirkan sifat tercela. Ia juga boleh dikatakan sebagai suatu peralihan daripada jiwa yang tercemar dengan dosa kepada jiwa yang suci. Proses Tazkiyah al-qalb perlu melalui beberapa fasa secara konsisten dalam mencapai ma'rifatullah. Fasa-fasa tersebut adalah altakhalli, al-tahalli dan al-tajalli. Tulisan ini berusaha menelusuri tazkiya al-qalb menurut ulama sufiyyah dengan berfokus pada maknatazkiyah alqalb, urgensi tazkiyah al-qalb, metode tazkiyahal-qalb, sarana tazkiyah al-qalb, dan buah tazkiyah al-qalb,
\end{abstract}

Kata kunci: Tzkiyah al-Qalb dan Ulama Sufiyyah

\footnotetext{
${ }^{158}$ Mahasiswa jurusan ushuludin smeter VII STAI AL FITHRAH Surabaya Jl. Kedinding Lor 30 Surabaya 60129.

${ }^{159}$ Ahmad Saifuddin Aman, Tasawuf Refolusi Mental-DzikirMengelolah Jiwa dan Raga (Tangerang : 2014), 77.
} 


\section{PENDAHULUAN}

Dalam kehidupan modern dengan teknologi yang berkembang saat ini, manusia semakin mengetahui sesuatu hal yang belum diketahui oleh para pendahulunya melalui teknologi yang diciptakannya. Jika kita berfikir sejenak maka akan terlintas dalam benak kita bahwa adakekuasaan serta keagungan Tuhan yang Maha Esa dan begitu kecil tentang pengetahuan kita tentang ciptaan-Nya. Oleh sebab itu sebagai makhluk ciptaan-Nya kita harus mencintai dan mengabdikan diri kepadaNya agar dapat selalu berada didekat-Nya.

Manusia memiliki pancaindra (anggotatubuh), akal fikiran dan hati sanubari sebagaimana yang telah dikemukakan oleh Ibn Khaldun. Ketiga potensi ini harus bersih, sehat dan dapat bekerjasama secara harmonis. Untuk menghasilkan kondisi seperti ini ada beberapa ilmu yang berperan penting bagi manusia. Pertama, ilmu Fiqih yang berperan dalam kebersihan dan kesehatan anggota tubuh. Kedua Filsafat yang berperan dalam menggerakan dan meluruskan akal fikiran. Ketiga ilmu Tasawuf yang berperan dalam membersihkan dan mengantarkan hati. ${ }^{160}$ Salah satu istilah yang banyak dibicarakan dalam kitab tasawuf adalah qalb (hati). Dalam dunia tasawuf, hati dipandang sebagai sumber kebaikan serta kejahatan, sumber pemahaman tentang keagamaan, dan tempat hadirnya sang Ilahi. Menurut para ulama, hati merupakan sumber pengetahuan tentang Tuhan, alam semesta dan manusia. Sesuai dengan makna dasarnya istilah hati dalam Al Quran merujuk pada tempat kebaikan serta kejahatan, kebenaran serta kesalahan dan keimanan serta kekufuran. ${ }^{161}$

\section{وَاللهُ يَعْلَمُ مَا فِيْ قُلُلُْ بَكُمْ}

\footnotetext{
${ }^{160}$ Abuddin Nata, Akhlak Tasawuf (Jakarta: Raja Grafindo Persada, 2006), 177.

${ }^{161}$ Nurcholis Madjid, Ensiklopedi Islam Untuk Pelajar,jld.2 (Jakarta: PT Ichtiar Baru van Hoeve, 1998), 94.
} 
"Allah Maha mengetahui apa yang ada di dalam hati kalian semua", 162

Dari uraian diatas, penulis ingin membahas serta menggali lebih dalam tentang penyucian hati agar menjadi qolbun salim menuju kehadirat Allah SWT dalam persfektik ulama sufiyyah. Semoga tulisan ini bermanfaat, meresap kedalam hati dan menjadi simpanan yang berharga kelak di akhirat, amin yaa Robbal 'alamin.

\section{TERAPI SPIRITUAL MELALUI TAZKIYAH AL-QALB PERSPEKTIF ULAMA SHUFIYYAH}

\section{Tazkiyah al-Qalb}

Tazkiyah al-Qalb merupakan tarkib idafi yang tersusun dari dua kata, Penyucian (al-Tazkiyah) dalam bahasa Arab berasal daripada perkataan zaka berarti suci. Al-Tazkiyah ( التنْكَيَّة ) berarti tumbuh, suci dan berkat. ${ }^{163}$ Contoh perkataan zakat disebut sedemikian kerana ianya kembali kepada berkah, atau menyucikan hati/jiwa, membersihkannya daripada sifat kikir ( شُخ ) atau keduanya. Zakaa terbentuk daripada dua kata benda yang merupakan gabungan antara

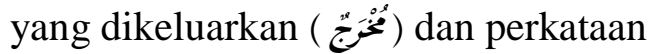

perbuatan ( فِ فِ ( ). Secara khusus iadiartikan sebagai harta yang dibayarkan untuk zakat. Secara istilahnya membawa maksud penyucian. ${ }^{164}$

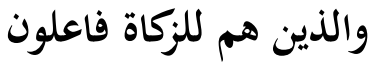

dan mereka yang berusaha membersihkan hartanya (dengan menunaikan zakat harta itu).

\footnotetext{
${ }^{162} \mathrm{Al}-\mathrm{Quran}, 33: 51$.

${ }^{163}$ Jamal al-Din Ibn Muhammad Ibn Makram Ibn Manzur, Lisan al-'Arab, jil. 16 (Beirut: Dar Sadir, t.t), 358.

${ }^{164}$ Al-Quran, $23: 4$.
} 
Berdasarkan penelitian yang telah dilakukan, terdapat enam ayat al-Quran yang telah mengungkapkan kalimah perkataan tazkiyah dalam konteks makna yang hampir serupa dan saling berkaitan. Antara yang dapat disimpulkan dari pada ayat-ayat tersebut, ialah membawa pengertian sifat Allah SWT yang berhak menyucikan dan mengaruniakan taufiq dan hidayah kepada manusia di dunia. ${ }^{165}$

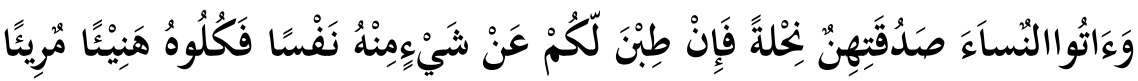

Berikanlah maskawin (mahar) kepada wanita (yang kamu nikahi) sebagai pemberian dengan penuh kerelaan. Kemudian jika mereka menyerahkan kepada kamu sebagian dari maskawin itu dengan senang hati, maka makanlah (ambilah) pemberian itu (sebagai makanan) yang sedap lagi baik akibatnya.

\section{Hamba yang Berjaya menyucikan jiwanya serta menyucikan makanannya. ${ }^{1}$

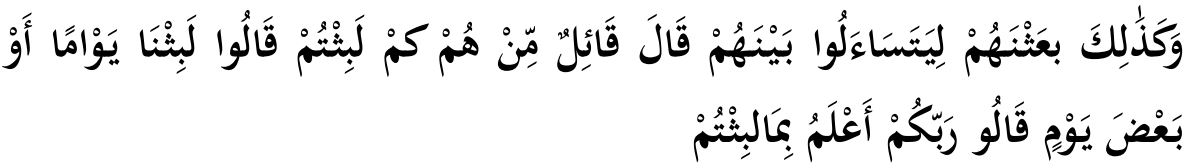

Dan demikianlah kami bangunkan mereka, agar mereka saling bertanya diantara mereka sendiri. Berkatalah salah seorang di antara mereka: sudah berapa lamakah kamu berada (disini?). "mereka menjawab: "kita berada (disini) sehari atau setengah hari." Berkata (yang lain lagi): "Tuhan kamu lebih mengetahui berapa lamanya kamu berada (disini). Maka suruhlah salah seorang di antara kamu untuk pergi ke kota dengan membawa uang perakmu ini, dan hendaklah dia lihat manakah makanan yang lebih baik, maka hendaklah ia membawa makanan itu untukmu, dan hendaklah ia berlaku

165 Al-Quran, 4 : 4.

${ }^{166}$ Al-Quran, $18: 19$. 
lemah-lembut dan janganlah sekali-kali menceritakan halmu kepada seorangpun.

Dan terakhir, makna yang membawa kepada konsep penyucian manusia yang selalu memuji dirinya sendiri. ${ }^{167}$

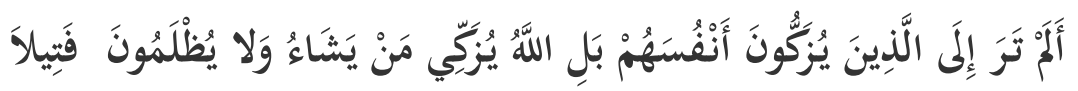

Apakah kamu tidak memperhatikan orang yang menganggap dirinya bersih? Sebenarnya Allah membersihkan siapa yang dikehendaki-Nya dan mereka tidak aniaya sedikitpun.

Menempati maksud tazkiyah sebagai penyucian, pembersihan dan penyuburan diri serta penyingkiran segala bentuk perkembangan yang tidak dikehendaki juga segala perkara yang tidak baik. Sedangkan al-Qalb memiliki makna hati yang memiliki beberapa sifat Sabu'iyah, Bahimiyah, Syaithaniyah dan Rabbaniyyah. kata al-qalb didalam al-Quran dan perubahannya (Tashrif) di temukan 169 kali. Hal ini menunjukan betapa penting istilah ini kita fahami dengan sebaik-baiknya. ${ }^{16}$

Kemudian lafad qulub jama' dari lafad qalbu yang berarti hati. istilah Ruh, Qalb, Aql dan Nafs sama-sama mempunyai dua makna. Kata qalb bermakna hati dalam bentuk fisik maupun hati dalam bentuk non fisik. hati dalam bentuk fisik adalah bagian tubuh manusia yang sangat penting karena penjadi pusat aliran darah ke seluruh tubuh, darah ini pula yang membawa kehidupan, oleh karena itu Rasulullah bersabda: "Sesungguhnya dalam diri manusia terdapat segumpal daging, jika gumpalan daging itu bagus maka akan baguslah

${ }^{167}$ Al-Quran, $4: 49$

${ }^{168}$ Yang dimaksud di sini ialah orang-orang Yahudi dan Nasrani yang menganggap diri mereka bersih. Lihat surat Al Baqarah ayat 80 dan ayat 111 dan surat Al Maa-idah ayat 18.

169 Muchtar Adam, Tazkiyah Mensucikan jiwa, Merdam Hawa Nafsu.(Bandung: Makrifat Media Utama). 67. 
seluruh anggota tubuh, jika gumpalan daging itu rusak maka akan rusak pula seluruh anggota tubuh. ketahuilah, gumpalan daging itu adalah jantung (Qalb)." Berdasarkan hadits ini sebenarnya tidak tepat kalau Qalb itu di artikan dengan hati, tetapi yang tepat adalah jantung. Lalu muncul hati yang bisa sedih, suka menangis, atau suka tersinggung. Berikutnya di jelaskan bahwa hati kita inilah yang menentukan seluruh kepribadian kita. kalau hati kita bersih, akan bersihlah seluruh akhlak kita. Yang ini bukan hati dalam pengertian fisik, akan tetapi hati dalam pengertian ruhani. Oleh karena itu, ada makna hati yang kedua, yaitu : Lathifah Rabbaniyah Ruhaniyyah. (sesuatu yang lembut yang berasal dari Tuhan dan bersifat ruhaniyah), lathifah itulah yang membuat kita mengetahui atau merasakan sesuatu kata Al-Qur'an, hati itu mengetahui merasakan, juga memahami, jadi hati adalah suatu bagian ruhaniyah yang kerjanya memahami sesuatu, itulah Qalb. Menurut para sufi, hati juga merupakan bagian dari diri kita yang dapat menyingkap ilmu-ilmu ghaib, ada riwayat yang menyebutkan bahwa kita mempunyai dua pasang mata: yaitu mata lahir dan mata bathin, jadi hati adalah lathifah yang mempunyai mata untuk bisa melihat atau menembus hal-hal yang ghaib. ${ }^{170}$

Tazkiyah al-Qalb secara bahasa memiliki arti mensucikan, membersihkan, dan memperbaiki hati. Sedangkan secara istilah tazkiyah al-Qalb memiliki makna sebagai berikut:

Pertama, Imam Qatadah beliau berkata "beramal kebaikan dan mensucikan hatinya dengan ketaatan kepada Allah swt.

Kedua, Imam Ibnu Qutaubah beliau berkata “ Menumbuhkan dan meninggalkan hati dengan ketaatan, kebajikan, sedekah, dan melakukan perbuatan ma'ruf nahi mungkar.

Ketiga, Imam Juraij dan Muqatil bin Hayan beliau berkata mensucikan hati dari kotoran kekufuran dan dosa-dosa.

Keempat, Imam Hasan al-Bashri beliau mengatakan "mensucikan, membersihkan, memperbaiki, dan membawa hati selalu dia ats ketaatan Allah swt.

${ }^{170}$ Muhammad al-Ghozali, Ihya' Ulumuddin (Semarang : Maktabah Usaha Keluarga, Tth), 3-5. 
Kelima,Ibnu katsir "mensucikan hati dengan taat kepada Allah dan membersikannya dari akhlak yang rendah dan hina.

Keenam,Syaikh Abdurrahman bin Nashir As-Sa'di beliau juga berkata "selalu mendidik hati di atas amal-amal ketaatan dan berlepas dari amal-amal atau pekerjaan yang mengajak suatu keburukan.

Dari definisi tazkiyah al-Qalb yang telah di utarakan para ulama sufiyyah di atas, telah diperkembangkan kepada satu simpulan pengertian yang lebih spesifik sebagai satu term spiritual. Tazkiyah mengandungi makna usaha gigih secara bersungguh-sungguh untuk membersih dan menyucikan hati seseorang manusia dari pada sifatsifat buruk dan keji (madhmumah) yang menjadi penghalang kepada penyuburan akhlak mulia (mahmudah) seseorang insan. Seterusnya penyucian hati itu diikuti dengan usaha pengisian dan perhiasan diri dengan akhlak mahmudah supaya proses tersebut menjadi lebih sempurna. mengarah pada suatu kesimpulan yang sama, yaitu tazkiyah al-qalb ialah uapaya pembinaan dan pendidikan hati untuk selalu mensucikan, memperbaiki, dan memuliakan hati dengan melaksanakan iman, tauhid, amal ketaatan, dan akhlak-akhlak yang mulia, selalu menjauhi perbuatan syirik, kufur, dosa-dosa dan akhlak yang tercela. ${ }^{171}$ (nyari buku)

Tazkiyah al-Qalb adalah suatu adalah kewajiban yang sangat penting, dan seagung-agung metode pendekatan kepada Allah swt (taqarrub) maka wajib bagi setiap muslim untuk merealisasikannya pada setiap tempat dan waktu, dimana hal ini akan memperkokoh syu'ab al-Iman (cabang-cabang iman) maka jika tazkiyah ini hilang niscaya sirnalah iman tersebut. ${ }^{172}$ sebagaimana kesalehan amal-amal yang lain tergantung kepada kesalehan hati ialah tazkiyah al-qulb, sedang anggota badan mengikutinya.

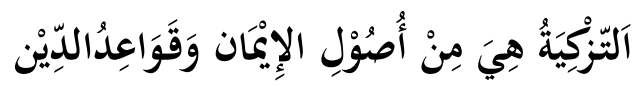

171 Ibid 16-17.

172 Muchtar Adam, Tazkiyah Mensucikan jiwa, Merdam Hawa Nafsu. (Bandung: Makrifat Media Utama). 70. 
Tazkiyah adalah bagian dari pokok keimanan, dan kaidah-kaidah agama.

Ibnu Taimiyah mengungkapkan tazkiyah al-Qalb adalah pokokpokok iman dan kaidah agama seperti: Mencintai Allah dan Rasulnya, tawakkal kepada Allah, mengikhlaskan agama kepada Allah, Syukur kepada Allah, sabar terhadap hokum-hukum Allah, takut kepada Allah dan penuh harap. ${ }^{173}$

Allah swt. berfirman dalam al-Qur'an. ${ }^{174}$

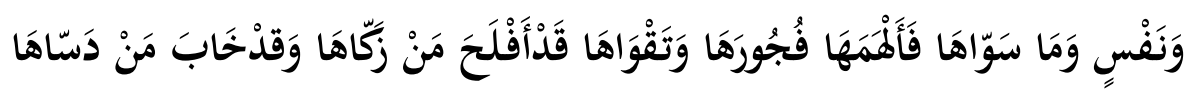

"dan jiwa serta penyempurnaan (ciptaannya), maka Allah mengilhamkan kepada jiwa itu (jalan) kefasikan dan ketaqwaannya, sesungguhnya beruntunglah seseorang yang mensucikan jiwa itu, dan sesungguhnya merugilah orang yang mengotorinya".

Kemudian firman Allah swt. yang menyebutkan keutamaan Nabi Muhammad saw. sebagai seorang yang mendidik dan menyucikan umatnya serta membawa kepada jalan yang benar. ${ }^{175}$

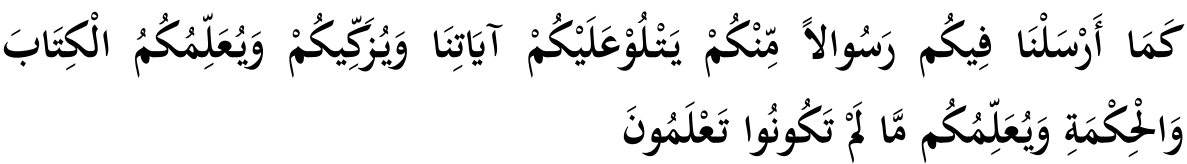

"Sebagaimana (kami telah menyempurnakan nikmat kami kepadamu) kami telah mengutus kepadamu Rasul diantara kamu yang membacakan ayat-ayat Kami kepada kamu dan

${ }^{173}$ Muhammad Shaleh al-Munjid, Silsilah A'mal al-Qulub., (Kairo : Daral-Fajri Cet. I 2005). 4.

174 Al-Quran, $91: 7-10$.

175 Al-Quran, $2: 151$. 
mensucikan kamu dan mengajarkan kepadamu al Kitab alHikmah, serta mengajarkan kepada kamu apa yang belum kamu ketahui”. (QS. Al-Baqarah: 151). ${ }^{176}$

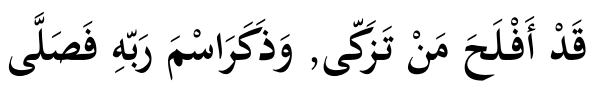

"sesungguhnya beruntunglah orang yang membersihkan diri (dengan beriman), dan dia ingat nama Tuhannya, lalu dia mendirikan shalat." (QA. Al-A'laa: 14-15).

Allah SWT meletakkan dimensi ketuhanan-Nya di dalam hati manusia, melalui hati Allah SWT selalu membisikkan kebenaran yang akan selalu mengarahkan manusia terhadap perilaku yang mulia. Jika manusia menolak, maka hati manusia akan tertutup dan akan jauh dari kebenaran. Dalam sebuah hadits yang diriwayatkan oleh Imam Bukhari dan Muslim, dari Abdullah bin Nu'man ra, Rasulullah SAW bersabda:

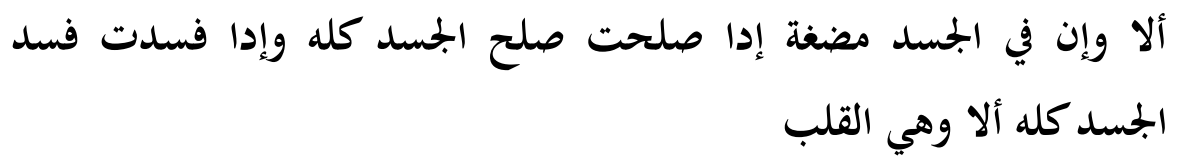

" ketauhilah bahwa dalam jasad itu terdapat sekerat darah, yang apa bila ia baik maka baik pula seluruh jasadnya. Dan apabila ia buruk, maka buruk pula selurh jasadnya. Ketahuilah bahwa sekerat darah tersebut adalah hati. (HR. Bukhari Muslim). ${ }^{177}$

Sangat diherankan jika seseorang menaruh perhatian kepada wajahnya yang merupakan sasaran pandang manusia, sementara itu ia

${ }^{176}$ Umar bin Muhammad al-Hafidz, Mengendalikan Nafsu dan Membentuk Budi Pekerti, (Surabaya: Cahaya Ilmu, 2012), x.

${ }^{177}$ Amin Syukur, Terapi Hati (Jakarta : Erlangga, 2012), ix. 
malah tidak sama sekali menaruh perhatian terhadap hatinya yang merupakan pandangan Allah terhadap hambanya. Karena sesungguhnya hatilah sasaran pandangan Allah terhadap hambanya.

Kemudian pendapat para ulama' sufi seperti Imam Ibnul Qayyim al Jauziyah menyebutkan bahwa manusia itu terbagi menjadi dua golongan:

1. Golongan yang terkalahkan oleh nafsunya, sehingga setiap perilakunya dikendalikan leh hawa nafsunya.

2. Golongan yang mampu mengekang dan mengalahkan nafsunya sehingga nafsu tersebut tunduk pada perintahnya.

Sebagian 'Arifin (orang-orang yang berma'rifah kepada Allah swt.) menyebutkan, "Barang siapa yang berhasil mengalahkan nafsunya maka beruntunglah ia. Sebaliknya, jika seseorang telah terkalahkan oleh hawa nafsunya maka merugi lah dan akan hancurlah ia." $" 178$

Secara metode dalam tazkiyah al-qalb perspektif Hadrotus Syaikh dan ulama' salaf tidaklah ada perbedaan secara subtansi. Akan tetapi beliau menjelaskannya lebih bertahap, sesuai dengan posisi kedudukan seorang hamba menuju Allah. Semua penjelasan Hadrotus Syaikh tentang tahapan-tahapan menuju kehadirat Allah adalah rahmat kasih saying, karena begitu banyak sesorang yang telah merasa sampai kepada Allah akan tetapi ia tidak melaksanakan perintah-Nya dan menjauhi larangan-Nya. Hadrotus Syaikh berkata: "kelapangan dan ketentraman jiwa tidak akan teraih kecuali setelah kepayahan, dan tidak akan terwujud kecuali dengan dicari".

Adapaun penyakit hati itu adalah sesuatu yang samar, pemiliknya mungkin tidak mengatahui karena mereka melalaikannya. Adapun jika dia telah mengetahuinya maka sulit banginya untuk bersabar menelan pahitnya obat, karena obatnya adalah menyelisihi hawa nafsu. Meskipun dia bisa menahan namun tetap tidak ada dokter yang ahli untuk mengobatinya,karena para dokter di bidang ini adalah para ulama dan penyakit itu sendiri sudah mengungkungi mereka, dan

${ }^{178}$ Ibid,. 10.

${ }^{179}$ Achmad Asrori al-Ishaqy, Untaian Mutiara Jilid V, H. 248. 
dokter tersebut jarang dilirik pengobatannya. Sebab itu penyakitmya menjadi kronis, ilmu tentang hal ini mulai tergerus, penyakit hati dan pengobatannya terlihat asing, seseorang melakukan amal-amal yang sepintas adalah ibadah, namun batinnya adalah adat (rutinitas dan kebiasaan) semata, nilah tanda-tanda dasar dalam penyakit hati. ${ }^{180}$

Ketika Allah telah menghendaki suatu kebaikan kepada hambanya, maka Ia akan membuat dirinya melihat aib (kekurangankekurangan) dirinya, dan ketika seseorang telah mengetahui aibnya maka kemungkinan ia akan mengobatinya. Akan tetapi kebanyakan manusia tidak mengetahui aib-aibnya diri mereka sendiri. Adapun beberepa cara agar seseorang ingin mengetahui kekurangannya diantaranya ialah :

Pertama, bersama dengan seseorang ( syaikh) yang memiliki mata batin (bashirah) yang tajam terhadadap sesuatu perkara aib-aib diri seseorang, yang akan membuka aib-aibnya kepadanya dan memberikan cara untuk untuk pengobatannya. Seseorang atau guru seperti ini sudah jarang di zaman seperti ini, barang siapa yang menemukan maka ia telah menemukan seseorang dokter yang ahli dan tidak patut untuk meninggalkannya.

Kedua, seseorang harus mencari teman yang jujur, memiliki bashirah dan teguh dalam beragama, menjadinya sebagai penelaah terhadap dirinya dan menunjukkannya kepada akhlak-akhlak dan perbuatan-perbuatannya yang tidak baik.

Ketiga, mengetahui aib-aib diri dari seseorang yang tidak suka terhadap kita, karena mata seseorang yang benci menampakkan sedikit keburukan, bisa jadi pemhambilan manfaat itu dari sesorang yang benci terhadap kita yang telah membuka aibnya lebih besar daripada pemanfaatannya dari seseorang yang berpura-pura menyembunyikan aibnya.

Keempat, dan bergaul dengan manusia, makaapa saja yang terihat tercela dari mereka, bisa dia jauhi. ${ }^{1}$

180 Ibnu qudamag al Maqdisi, Muhktashar Minhajul Qashidin (Jakarta: Darul Haq, 2015). 284-285.

${ }^{181}$ Muhammad al-Ghozali, Ihya' Ulumuddin jilid III (Semarang : Maktabah Usaha Keluarga, Tt). 62-63. 
Di dalam kitab An Nuqhtah Wal Baaqiyatush Sholihat Wal 'Aaqibatul Khoirot Wal Khootimatul Hasanat, Hadrotus Syaikh juga menjelaskan tentang jalan-jalan yang sangat istimewah untuk wushulsampai kehadirat Allah swt dan fana fillah (hilang dan sirna rasa kemanusiaannya akibat ber-musyahadah hanya kepada Allah). Beliau berkata bahwasanya jalan yang sangat istimewah untuk wushul kehadirat yaitu: Pertama, mencintai Guru Mursyid yang hakiki, sempurna, membimbing dan menuntun dengan penuh karisma dan dayatarik (setrum), cara yang pertama ini adalag cara yang paling luhur dan kuat. Kedua, Robithoh. Ketiga, selalu menjelaskan dzikir yang telah dibimbing dan dituntun oleh Syaikh al-Murobbi al-Mursyid secara Istiqomah dan thuma'ninah. Keempat, muroqobah.

Imam al-Ghozali dalam bukunya menjelaskan tazkiyah al-qalb dapat direalisasikan apabila seseorang itu dapat meleraikan serta melumpuhkan penyakit-penyakit hati serta membersihkan dirinya dari sifat-sifat buruk atau pun sifat-sifat yang tercela sehingga hatinya dapat dibebaskan daripada segala sesuatu yang tidak baik. ${ }^{183}$ Beliau telah menggariskan tiga belas cara yang perlu dilakukan ketika melalui proses tersebut di dalam kitabnya "Ihya' 'Ulum al-Din". Di antaranya adalah solat, mengeluarkan zakat, puasa, mengerjakan ibadah haji, membaca al-Quran, berzikir, bertafakkur terhadap keindahan alam, mengingat mati, memendekkan angan-angan, muraqabah, muhasabah serta mu'atabah, amar makruf dan nahi munkar, khidmat dan tawaddu', mengetahui pintu masuk syaitan kedalam jiwa dan cara mencegahnya, dan akhir sekali ialah mengetahui penyakit-penyakit hati dan cara merawatinya.

Secara ringkasnya hanya ingin menjelaskan beberapa cara yang telah digariskan oleh Imam al-Ghazali di atas secara lebih terperinci. Pertama, solat adalah cara yang paling utama dalam pembersihan hati atau jiwa. Solat menurut beliau merupakan satu cara atau matlamat yang menggabungkan di antara hakikat 'ubudiyyah, tauhid, syukur dan lain-lain lagi disertai dengan amalan zahir seperti zikir, berdiri

182 Achmad Asrori al-Ishaqy, An Nuqhtah Wal Baaqiyatush Sholihat Wal 'Aaqibatul Khoirot Wal Khootimatul Hasanat.

${ }^{183}$ Ibid., 48-49. 
(qiyam), ruku', sujud, tahiyyah dan sebagainya. Dengan kata lain yang lebih mudah untuk difahami ialah, dengan tertegaknya jasad, ia akan membawa kepada ketundukan jiwa sekali gus menyingkirkan sifat angkuh, 'ujub, dan sifat-sifat madhmumah yang lain di dalam diri seseorang. Aspek kerohanian yang paling utama ketika menunaikan solat ialah 'khushu'. Tanpa 'khushu', seseorang itu tidak akan dapat mencapai objektifnya dalam proses 'tazkiyah al-qalb'. Imam alGhazali telah menjelaskan secara panjang lebar mengenai hal ini dalam kitabnya "Ihya' 'Ulum al-Din". Dalam hal ini, beliau telah memetik beberapa dalil al-Quran bagi menguatkan lagi hujahnya sebagaimana firman Allah SWT di dalam al-Quran al-Karim.

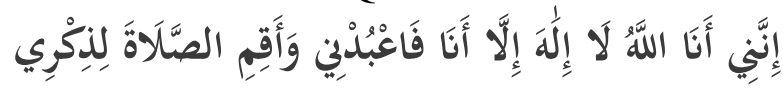

Maksudnya: Sesungguhnya Aku ini adalah Allah, tidak ada Tuhan (yang hak) selain Aku, maka sembahlah Aku dan dirikanlah sholat untuk mengingat-Ku.

Daripada ayat di atas jelas membuktikan bahawa mengingati Allah di dalam sholat merupakan satu kewajipan. Sikap lalai dan leka adalah berlawanan dengan mengingati, dan orang-orang yang lalai ketika sholat tidak akan mampu untuk menghadirkan hati dalam mengingati Allah SWT. Sesungguhnya sholat dalam keadaan yang lalai serta jiwa yang kosong tanpa lahirnya perasaan takut kepada Allah SWT tidak akan mampu melahirkan kekuatan dan tumpuan kepada Tuhannya bagi mencegah kemungkaran.

Kedua, puasa. Puasa merupakan salah satu cara yang diperkenalkan oleh beliau melalui proses tazkiyah al-qalb. Menurutnya, puasa memainkan peranan utama dalam melatih diri supaya bersabar dan bersederhana dalam segala hal. Terutama sekali dalam urusan mengendali kehendak hawa nafsu yaitu nafsu perut dan nafsu kemaluan. Hal ini adalah kerana hawa nafsu akan menjadi kuat melalui makanan dan minuman yang diambil, lebih-lebih lagi jika ia

Al-Quran, 20:14. 
diambil secara berlebihan. Oleh yang demikian, kita perlu menyempitkan jalan masuk syaitan dengan cara berlapar ataupun menahan diri daripada makan dan minum, puasa juga mempunyai kedudukan istimewa.

Ketiga, salah satu cara lain yang telah digariskan oleh Imam alGhazali ialah berzikir. Ibadah yang lebih utama dan digalakkan untuk melakukannya setelah membaca al-Quran adalah dengan berzikir mengingati Allah SWT. Ia telah ditegaskan di dalam al-Quran alKarim dengan firman Allah SWT. ${ }^{185}$

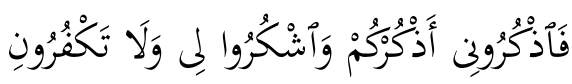

Kerana itu, ingatlah kamu kepada-Ku nescaya Aku ingat (pula) kepadamu, dan bersyukurlah kepada-Ku, dan janganlah kamu mengingkari (nikmat)-Ku.

Tuntutan untuk berzikir sebenarnya bukanlah hanya sekadar menyebut nama Allah SWT sahaja di bibir, malah hendaklah dilakukan sehingga diri merasakan bahawa segala tindak-tanduk yang dilakukan berada di dalam pemerhatian Allah. Maka, seseorang individu itu akan berasa takut serta tidak tergamak untuk melakukan perkara-perkara yang berdosa dan perbuatan maksiat terhadap Allah SWT. ${ }^{186}$

Cara yang seterusnya ialah dengan bertafakkur terhadap kejadian alam. Menurut al-Ghazali berfikir adalah merupakan anak kunci untuk memperolehi 'nur' atau cahaya petunjuk terhadap sesuatu perkara. Ia merupakan pokok penglihatan mata hati serta alat untuk mencapai ma'rifah, ilmu pengetahuan dan pengalaman. Sebagian para ulama sufiyyah menekankan kepentingan "tafakkur" seseungguhnya dengan bertafakkur, maka akan lahirlah pengagungan terhadap

185 Al-Quran, 2 : 152.

186 Abdullah Gymnastiar, Mencari Ketenangan Jiwa, terj. Ainun Najah Ali, (Kuala Lumpur : Mustread Sdn.Bhd, cet. Ke-2, 2011), 15-22. 
kebesaran Allah SWT yang mana jika tanpa qudrah dan iradah serta kemurahan-Nya, segala yang wujud di muka bumi ini tidak akan dapat dinikmati oleh manusia dan makhluk-makhluk lain yang telah diciptakan oleh-Nya.

Cara terakhir yang telah dibawa oleh al-Ghazali adalah mengetahui penyakit-penyakit hati serta mengetahui cara untuk merawatinya. Menurut beliau, hati yang sakit adalah hati yang tidak dapat berfungsi sebagaimana yang dikehendaki seperti berilmu, berhikmah, mencintai Allah lebih daripada mencintai sesuatu yang lain, menggerakkan anggota badan untuk beribadah kepadaNya serta merasakan kelazatan tatkala bibir berzikir menyebut namaNya. Manakala, antara sifat-sifat madhmumah yang telah disebutkan oleh Imam al-Ghazali di dalam kitabnya "Ihya' 'Ulum al-Din" ialah riya', takabbur, sukakan kemegahan dan pujian, kikir, dengki, mengumpat, berdusta dan sebagainya. ${ }^{1}$

Imam al-Junayd merupakan seorang tokoh sufi yang berpegang kuat dengan al-Quran dan al-Hadith. Beliau dikatakan sebagai seorang ahli sufi yang mana merupakan orang yang mula-mula menyusun ilmu tasawuf sehingga tertegaknya satu mazhab kerohanian yang diakui oleh Islam. Sumbangannya terlalu banyak dalam menghasilkan ratusan ribu kitab-kitab karangan para ulama' yang membicarakan tentang ajaran tasawuf. ${ }^{188}$

Al-Junayd juga telah memperkenalkan beberapa metode berkaitan konsep 'tazkiyah al-Qalb'. Yang pertama sekali ialah, seseorang itu mestilah berpegang teguh kepada al-Quran dan alHadith. Menurutnya, seseorang yang ingin melakukan 'tazkiyah alQalb' mestilah berpegang kuat terhadap ajaran al-Quran dan alHadith. Beliau menekankan aspek penghayatan dan juga pengetahuan terhadap suri teladan yang telah ditinggalkan oleh Rasulullah SAW.

187 Imam al-Ghazali, 'Ibadah Perspektif Sufistik, terj. Muhtar Holland, (Surabaya: Risalah Gusti, 1999), 66.

188 Rushita Rejab, "Tazkiyyah al-Nafs : konsep dan keberkesanannya di kalangan Mahasiswa Akademi Pengajian Islam Universiti Malaya”, (Disertasi,Jabatan Akidah dan Pemikiran Islam,Bahagian Pengajian Usuluddin, Akademi Pengajian Islam, Universiti Malaya, 2000/2001), 70-75. 
Hal ini adalah kerana beliau menyedari bahwa terdapat kebanyakan manusia yang tersesat kerana tidak mengamalkan atau menghayati sesuatu yang diketahui dan dipelajarinya. Sebagaimana telah dijelaskan oleh Imam Malik yang mana beliau meriwayatkan dalam kitab al-Muwatta secara mursal katanya, Rasulullah SAW bersabda:

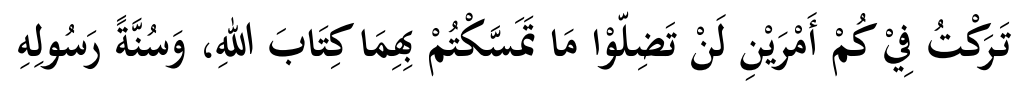

"Aku tinggalkan kepada kamu dua perkara: kamu sama sekali tidak akan sesat selama kamu berpegang kepada kedua-duanya: Kitab Allah dan Sunnah Rasulnya”.

Jelaslah di sini bahwa pengetahuan yang mendalam mengenai al-Quran dan al-Hadith adalah amat penting kepada setiap muslim dalam melalui proses 'tazkiyah al-qalb' yaitu untuk menyucikan diri daripada perkara-perkara yang dilarang Allah serta ia juga dapat dijadikan penyelamat daripada digoda dan diselewengkan oleh syaitan yang durjana.

Metode yang kedua yang telah diperkenalkan oleh al-Junayd ialah menghiasi diri dengan akhlak yang mulia dan menjauhkan diri daripada akhlak yang keji serta mengabdikan diri kepada Allah SWT. Menurutnya, antara sifat mahmudah yang perlu diterapkan di dalam diri adalah seperti zuhud, reda, qana'ah dan sebagainya, sedangkan antara sifat madhmumah yang perlu dihindari menurutnya ialah sombong, takabbur, riya' dan sebagainya. Selain itu, menurut alJunayd juga, metode tazkiyah al-qalb yang merujuk kepada pengabdian diri kepada Allah ialah dengan taubat. Menurutnya, hakikat atau tabi'i taubat dengan melupakan dosa. Golongan yang bertaubat merupakan kekasih Allah yang mana mereka merupakan golongan yang sentiasa di dalam keadaan musyahadah terhadap Allah SWT. Sehubungan dengan ini, beliau telah mengatakan bahwa: ${ }^{189}$

${ }^{189}$ Ali Uthman Al-Jullabi Al-Hujwiri, The Kashf al-Mahjub; The Oldest Persian Tretise on Sufism, (London: Lucaz \& Co. Ltd, 1970), 297. 
"Aku telah membaca banyak kitab, tetapi aku tidak pernah menemui sesuatu yang lebih memberi panduan daripada katakata berikut; 'Apabila aku bertanya: "Apakah dosaku? Lalu jawapan yang diberikan: "Kewujudan engkau adalah suatu dosa, di mana tidak ada dosa lain yang boleh dibandingkan dengannya"

Dengan kata lain, cara atau metode menuju Allah SWT ialah dengan bertaubat. Ia merupakan jalan kerohanian yang amat ditekankan oleh beliau. Seseorang yang bertaubat akan berpindah dari suatu maqam ke maqam yang lain sehingga pada suatu masa ia akan berada hampir dengan Allah SWT. Sesungguhnya untuk mencapai kepada maqam tersebut, seseorang itu perlulah melakukan proses tazkiyah al-qalb terlebih dahulu. al-Junayd juga pernah menghuraikan mengenai tiga perkara utama yang menjadi metode dalam proses tazkiyah al-qalb yaitu, pertama, meninggalkan dunia, kedua, berpuasa sunat dan ketiga, berjaga malam untuk mengingati Allah SWT.

Al-Muhasibi merupakan seorang tokoh sufi yang besar dan amat pakar di dalam perbahasan mengenai tasawuf akhlak terutama mengenai hal-hal kejiwaan. Di dalam membahaskan aspek kejiwaan, beliau banyak memfokuskan tentang penyakit-penyakit hati atau gangguan-gangguan jiwa serta menjelaskan mengenai bahaya mengikutinya dan bagaimanakah caranya untuk membersihkan hati atau jiwa tersebut daripada pengaruh-pengaruh buruk.

Menurutnya, dalam membahaskan hal berkaitan proses 'tazkiyah al-Qalb', beliau amat menitik beratkan tentang mendisiplinkan diri dan beliau juga menyedari bahawa jalan penyucian itu termasuklah sikap takutkan akan Allah SWT, menunaikan segala yang diperintahkanNya dengan ikhlas, taat kepada-Nya dan mencontohi para rasul-Nya. Beliau juga berpendapat, untuk mencapai atau menggapai matlamat 'tazkiyah al-Qalb' seseorang itu perlulah berusaha serta sentiasa mengamalkan sifat-sifat mahmudah seperti reda, zuhud, sabar, syukur dan lain-lain lagi. Dengan adanya sifat mahmudah tersebut dalam diri seseorang individu, sudah pasti ia akan dapat mencapai matlamatnya yaitu menyucikan hati atau jiwa daripada kekotoran yang tercela. Hal ini 
adalah kerana jiwa merupakan suatu yang dominan dan memberi pengaruh yang besar sebagai penyebab berlakunya maksiat dalam diri manusia. ${ }^{190}$

Al-Muhasibi juga dalam metodenya telah memberikan nasihat kepada siapa yang ingin menyucikan hati atau jiwa agar sentiasa memeriksa keadaan al-qalb (hatinya). Seseorang yang ingin menyucikan hati atau jiwa juga perlulah memiliki i'tikad untuk sentiasa tawaddu' kepada Allah dan menghilangkan perasaan takabbur. ${ }^{191}$ Seseorang itu juga perlu memiliki serta menanamkan dalam diri sikap bersungguh-sungguh dan tekun dalam melakukan amal ibadah kepada Allah SWT. Justeru, dapatlah dikatakan di sini bahawa al-Muhasibi adalah seorang sufi yang amat peka terhadap kerohanian dan juga dalam menjaga adab terhadap Allah SWT. Beliau juga berpesan bahawa hendaklah seseorang itu berpegang teguh kepada ajaran al-Quran dan al-Hadith bagi menyelamatkan diri daripada kesesatan dan perilaku-perilaku hina dan buruk.

Tazkiyah hati dan jiwa hanya bisa dicapai melalui berbagai ibadah dan amal perbuatan tertentu, apabila seseorang melaksanakn secara sempurna dan memadai. Pada saat itulah terealisir dalam hati sejumlah makna yang menjadikan hati tersucikan dan memiliki sejumlah dampak dan hasil pada seluruh anggota badan seperti lisan, mata, telinga dan lainya. Hasil yang palin nyata dari hati yang tersucikan ialah adab dan mu'amalah yang baik kepada Allah dan manusia. Kepada Allah berupa pelaksanaan hak=hak-Nya termasuk di dalamnya mengorbankan jiwa dalam rangka jihad di jalan-Nya. Sedangkan terhadap manusia, sesuai dengan ajaran, tuntunan maqam dan taklif Ilahi. Jadi, Tazkiyah memiliki berbagai sarana seperti shalat, infaq, puasa, haji, tilawah al-Qur'an dzikir, bersholawat kehribaan

190 Siti Mahfuzah Shafiei, "Konsep Tazkiyyah Al-Nafs Dari Sudut Tasawuf Menurut Pandangan Al-Muhasibi", (Latihan Ilmiah, Jabatan Akidah dan Pemikiran Islam,Bahagian Pengajian Usuluddin, Akademi Pengajian Islam, Universiti Malaya, 2001/2002), 77-79.

${ }^{191}$ Ibid. 
Baginda Habibillah Rasulillah Muhammad saw, tafakkur, renungan, muhasabah dan dzikrul maut (mengingat mati). ${ }^{1}$

\section{MANFAAT TAZKIYAH AL-QALB}

setelah seseorang hamba telah berusaha dan bersungguh-sungguh dalam menyucikan hatinya agar menjadi hati yang Qolbun salim denga sarana tazkiyah al-qalb yang dilakukan secara sempurna dan memadai, maka akan membawa pengaruh besar terhadap penyucian hati. Pertama, seorang hamba akan menetapi budi pekerti yang mulia (akhlaqul karimah). Buah atau hasil dari ibadah penghambaannya kepada Allah swt., adalah budi pekerti yang mulia karena suatu akhlak yang mulia adalah sifat utama Bagi Baginda Habibillah Rasulillah Saw. Seperti sabda beliau yang artinya "Orang mukmin yang paling sempurna imannya adalah yang paling baik akhlaknya."

Kedua, seorang hamba akan meraih keberuntungan dan kebahagiaan, bahwa Allah telah mengisyaratkan dalam al'Quran penyucian jiwa sebagai kunci meraih keberuntungan dan kebahagiaan, Allah swt berfirman. ${ }^{193}$

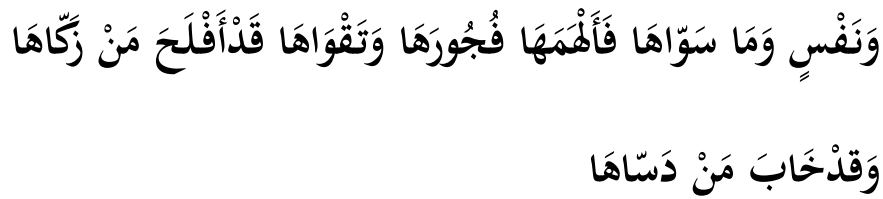

"dan jiwa serta penyempurnaan (ciptaannya), maka Allah mengilhamkan kepada jiwa itu (jalan) kefasikan dan ketaqwaannya, sesungguhnya beruntunglah seseorang yang mensucikan jiwa itu, dan sesungguhnya merugilah orang yang mengotorinya.

Ketiga, selamat dari kemurkaan dan siksaan Allah di hari kiamat, yaitu hamba-hambanya datang dengan hati yang suci. Jiwa yang ditazkiyah menggapai kesucian dan diselamatkan dari siksa neraka yang

${ }^{192}$ Sa'id Hawa, al-Mustakhlash Fi Tazkiyah al-Nafs, (Kairo: Dar al-Salam, 2001). 9.

${ }^{193}$ Al-Quran, 91 : 7-10 
bergejolak dasyat. Dan Allah juga menyediakan surga 'And yang tinggi bagi hamba-Nya yang telah mensucikan hati atau jiwanya.

\section{KESIMPULAN}

Berdasarkan dari pemaparan data di atas maka dapat di simpulkan, Adapun secara istilah Qalb adalah organ rohani manusia yang memiliki pengaruh paling banyak dan paling besar diantara anggota rohani lainnya yang mengeluarkan intruksi kepada anggota jasmani untuk melakukan suatu tindakan. tazkiyah al-qalb sebuah proses berupa upaya yang sunguh-sungguh dalam mensucikan hati ataupun jiwa dari segala penyakit dan kotoran hati, baik itu syirik dan derivasinya seperti riya' ujub, dan penyakit sombong dan penyakit hati laninya. Hawa nafsu adalah tangga menuju kesempurnaan manusia juga dapat memerosotkan manusia menuju kemenangan. Allah memuliakan manusia dengan iradah setiap langkah yang digerakkannya, berdasarkan iradah dan ikhtiar. Nilai perbuatan manusia berbanding lurus dengan usaha dicurahkan dalam kenyataannya kepada perintah Allah.

Sekian banyak orang seakan memuliakan hawa nafsunya dengan cara memenuhi setiap ajakannya, padahal dengan begitu, dia hanya akan merendahkan jiwanya sendiri, sebaliknya banyak juga orang yang bersikap keras, sinis, dan acuh tak acuh akan tuntutan hawa nafsunya. 


\section{DAFTAR PUSTAKA}

Adam, Muchtar, Tazkiyah Mensucikan jiwa, Merdam Hawa Nafsu, Bandung: Makrifat Media Utama.

Maqdisi (al), Ibnu qudamah, Muhktashar Minhajul Qashidin Jakarta: Darul Haq, 2015.

Ghazali (al), Imam, 'Ibadah Perspektif Sufistik, terj. Muhtar Holland, Surabaya: Risalah Gusti, 1999.

------------, Ihya' Ulumuddin, Maktabah Usaha Keluarga Semarang, Tth.

Jullabi Al-Hujwiri (al), Ali Uthman, The Kashf al-Mahjub; The Oldest Persian Tretise on Sufism, London: Lucaz \& Co. Ltd, 1970.

Ishaqy Asrori (al), Achmad. An Nuqhtah Wal Baaqiyatush Sholihat Wal 'Aaqibatul Khoirot Wal Khootimatul Hasanat.

Gymnastiar, Abdullah, Mencari Ketenangan Jiwa, terj. Ainun Najah Ali, Mustread Sdn.Bhd., Kuala Lumpur, cet. Ke-2, 2011.

Hawa, Sa'id, al-Mustakhlash Fi Tazkiyah al-Nafs, Kairo: Dar al-Salam, 2001.

Jamal al-Din Ibn Muhammad Ibn Makram Ibn Manzur, Lisan al-'Arab, jil. 16, Beirut: Dar Sadir.

Madjid, Nurcholis Ensiklopedi Islam Untuk Pelajar,jld.2, Jakarta: PT Ichtiar Baru van Hoeve, 1998.

Mahfuzah Shafiei, Siti, "Konsep Tazkiyyah Al-Nafs Dari Sudut Tasawuf Menurut Pandangan Al-Muhasibi", Latihan Ilmiah, Jabatan Akidah dan Pemikiran Islam,Bahagian Pengajian Usuluddin, Akademi Pengajian Islam, Universiti Malaya, 2001/2002.

Nata, Abuddin Akhlak Tasawuf, Jakarta: Raja Grafindo Persada 2006.

Rejab, Rushita, "Tazkiyyah al-Nafs : konsep dan keberkesanannya di kalangan Mahasiswa Akademi Pengajian Islam Universiti Malaya", Disertasi,Jabatan Akidah dan Pemikiran Islam,Bahagian Pengajian Usuluddin, Akademi Pengajian Islam, Universiti Malaya, 2000/2001.

Saifuddin Aman, Ahmad, Tasawuf Refolusi Mental-DzikirMengelolah Jiwa dan Raga, Tangerang 2014. 
Shaleh al-Munjid, Muhammad, Silsilah A'mal al-Qulub., Kairo DaralFajri Cet. I 2005.

Syukur, Amin, Terapi Hati, Jakarta Erlangga, 2012.

Umar bin Muhammad al-Hafidz, Mengendalikan Nafsu dan Membentuk Budi Pekerti, Surabaya: Cahaya Ilmu, 2012. 